\title{
Viabilidade do sêmen de tatus-peba (Euphractus sexcinctus) centrifugado e diluído em Tris ou agua de coco em pó
}

\author{
Viability of the six-banded armadillos (Euphractus sexcinctus) semen centrifuged and extended in \\ Tris or powdered coconut water
}

\author{
Patrícia da Cunha Sousa ${ }^{\mathrm{I}}$ Erika Aparecida Araújo dos Santos ${ }^{\mathrm{I}}$ Andréia Maria Silva ${ }^{\mathrm{I}}$ \\ Thibério de Souza Castelo ${ }^{\mathrm{I}}$ Gislayne Cristhiane Xavier Peixoto ${ }^{\mathrm{I}}$ Carlos Iberê Alves Freitas ${ }^{\mathrm{II}}$ \\ Alexandre Rodrigues Silva ${ }^{I^{*}}$
}

RESUMO

Foram avaliados os efeitos da centrifugação associada ao uso de dois diluentes na manutenção da viabilidade espermática em tatus-peba (Euphractus sexcinctus) ao longo do teste de termorresistência (TTR). Amostras de sêmen $(n=12)$, oriundas de 04 machos adultos coletados por eletroejaculação, foram divididas em quatro alíquotas, sendo duas imediatamente diluídas em Tris ou água de coco em pó (ACP-119 $\left.{ }^{\circledR}\right)$, e as outras duas centrifugadas $\left(800 \mathrm{~g}_{\left.10 \mathrm{~min}^{-1}\right)}\right.$ previamente à diluição. As amostras foram incubadas a $34^{\circ} \mathrm{C}$ por 3 h, e os parâmetros seminais avaliados em intervalos de $1 \mathrm{~h}$. Em termos gerais, verificou-se uma redução da viscosidade espermática imediata à diluição em ambos os diluentes, independente do uso da centrifugação. Aos 60 minutos, verificou-se uma redução dos parâmetros avaliados $(P<0,05)$, embora o Tris tenha promovido uma melhor preservação deles $(P<0,05)$, quando comparado ao ACP-119 ${ }^{\circledR}$ até os 120 minutos de avaliação. Após este período, os dois diluentes se equipararam $(P>0,05)$. Ainda, verificou-se um efeito deletério da centrifugação sobre a qualidade do sêmen de tatus-peba durante todo o teste de termorresistência. Nas condições do presente estudo, conclui-se que o diluente Tris mostrou-se superior ao ACP-119 ${ }^{\circledR}$ para a manutenção da viabilidade do sêmen de tatus-peba, sendo desnecessária a realização de centrifugação prévia à diluição.

Palavras-chave: tatu-peba, termorresistência, sêmen, centrifugação, diluentes.

\section{ABSTRACT}

The effects of the centrifugation associated to the use of two extenders on the viability of six-banded armadillo's (Euphractus sexcinctus) sperm were evaluated during a thermo resistance test (TRT). Semen samples $(n=12)$ derived from 04 stud males collected by electroejaculation were divided in four aliquots; two of that were immediately diluted in Tris or powdered coconut water $\left(\mathrm{ACP}-119^{\circledR}\right)$; the two others were centrifuged $\left(800 \mathrm{~g} 10 \mathrm{~min}^{-1}\right)$ prior to the dilution. Samples were incubated at $34^{\circ} \mathrm{C}$ per $3 \mathrm{~h}$, and the semen parameters were evaluated at each hour. In general, dilution promoted a reduction in semen viscosity in the use of both diluents using centrifugation or not. At 60min, a decrease was verified for all semen parameters $(P<0.05)$, however they were better preserved in the use of Tris when compared to ACP$119^{\circledR}(P<0.05)$ up to $120 \mathrm{~min}$. After that, both diluents equated. In addition, centrifugation procedure presented a deleterious effect on the armadillo's semen quality during all the thermoresistance test. In the present conditions, conclude that Tris extender is more efficient than ACP-119 ${ }^{\circledR}$ for the preservation of six-banded armadillo semen viability, and the previous centrifugation is unnecessary.

Key words: six-banded armadillo, thermoresistance, semen, centrifugation, extenders.

\section{INTRODUÇÃO}

Os Euphractus sexcinctus, conhecidos popularmente como tatus-peba ou tatus-amarelos, encontram-se distribuídos em praticamente todos os biomas brasileiros (ANACLETO et al., 2006). Haja vista não serem considerados sob ameaça de extinção, têm sido sugeridos como modelos experimentais para espécies filogeneticamente próximas e em risco de extinção, como os tatus-bola (Tolypeutes sp. - IUCN, 2013). Apesar da importância ecológica, estudos relacionados à reprodução dos tatus, bem como de todos os integrantes da ordem Xenartra, são escassos (HEATH et al., 1987; SERAFIM et al., 2010; SANTOS et al., 2011). Este fato tem limitado o desenvolvimento de tecnologias que possam

'Laboratório de Conservação de Germoplasma Animal (LCGA), Universidade Federal Rural do Semiárido (UFERSA), 59625-900, Mossoró, RN, Brasil. E-mail: alexrs@ufersa.edu.br. *Autor para correspondência.

IDepartamento de Ciências Animais, UFERSA, Mossoró, RN, Brasil. 
maximizar sua reprodução, como, por exemplo, a preservação de seus gametas seguida de inseminação artificial. Em adição, denota-se a necessidade de elaboração de diluentes adequados às características peculiares do sêmen de tatus-peba, tal como a elevada viscosidade do plasma seminal (SERAFIM et al., 2010; SANTOS et al., 2011; SOUSA et al., 2013).

Fatores relacionados com a elevada viscosidade são considerados limitantes durante o processamento do sêmen em outras espécies (MOSAFERI et al., 2005; OLIVEIRA et al., 2011). A fim de reverter essa problemática, foi descrita a liquefação do sêmen e manutenção da viabilidade espermática em camelos (Camelus bactrianus), empregando-se a diluição em solução a base de Tris (MOSAFERI et al., 2005), o qual já foi inclusive utilizado no próprio tatu-peba (SANTOS et al., 2011). Na busca de alternativas de menor custo, têm sido desenvolvidas soluções a base de água de coco $\left(\mathrm{ACP}^{\circledR}\right)$, que têm demonstrado eficiência tanto na liquefação seminal como na manutenção da viabilidade espermática em espécies silvestres, como os macacosprego (Cebus apela) (OLIVEIRA et al., 2011).

Adicionalmente, a centrifugação tem sido proposta como uma alternativa para remoção do plasma seminal e redução na contaminação por urina na amostra em várias espécies (ALVAREZRODRIGUEZ et al., 2013). Embora possibilite a adequação de taxas fidedignas de diluição, já foi demonstrado um efeito mecânico deletério dela sobre os espermatozoides de alguns mamíferos (CASTELO et al., 2010). Nos tatus, entretanto, o efeito da centrifugação sobre as amostra de sêmen permanece desconhecido.

Este trabalho objetivou avaliar o efeito da centrifugação associada ao uso dos diluentes a base de Tris ou água de coco em pó (ACP-119 ${ }^{\circledR}$ ) sobre a manutenção da viabilidade do sêmen de tatuspeba (Euphractus sexcinctus), ao longo do teste de termorresistência.

\section{MATERIAL E MÉTODOS}

O estudo foi realizado com animais provenientes do Centro de Multiplicação de Animais Silvestres - CEMAS da UFERSA (Registro IBAMA no 1478912), situado em Mossoró, RN, localizada na região semiárida brasileira $\left(5^{\circ} 10^{\prime} \mathrm{S}-37^{\circ} 10^{\prime} \mathrm{W}\right.$; temperatura: $27-29^{\circ} \mathrm{C}$ ). Foram utilizados quatro tatuspeba machos adultos, com idade aproximada de dois anos, pesando $3,25 \pm 0,2 \mathrm{~kg}$. Eles foram confinados em tanques individuais, mantidos sob fotoperíodo natural $(\sim 12 \mathrm{~h})$, alimentados uma vez por dia com ração para manutenção de cães $\left(\right.$ Pedigree $^{\circledR}$, MARS, Campinas, Brasil), acrescida de vegetais e água ad libitum. Exceto quando indicado, todas as substâncias utilizadas no experimento foram provenientes da Sigma-Aldrich, St. Louis, MO, USA.

Cada um dos quatro animais foi submetido a três procedimentos distintos de eletroejaculação em intervalos de 15 a 21 dias, perfazendo um total de 12 ejaculados. Para tanto, estes foram contidos com luvas apropriadas e medicados com xilazina (1mg $\mathrm{kg}^{-1}$ Sedomin $^{\circledR}$, König S.A., Buenos Aires, Argentina) e cetamina $\left(7 \mathrm{mg} \mathrm{kg}^{-1}\right.$ Quetamina Injetável, Vetnil ${ }^{\circledR}$, São Paulo, Brasil) por via intramuscular (músculo vasto lateral da coxa), seguindo-se a manutenção do estado anestésico por meio de aplicação intravenosa de propofol (5mg kg-1 (Propovan $^{\circledR}$, Cristalia, Fortaleza, Brasil) em bolus (AMORIM et al., 2012). Os animais foram posicionados em decúbito dorsal, realizando-se a higienização das regiões peniana e perianal com solução fisiológica. Utilizou-se um eletroejaculador (Eletrojet ${ }^{\circledR}$, Eletrovet, São Paulo, SP, Brasil), conectado a uma fonte de $12 \mathrm{~V}$, promovendose três ciclos sucessivos de estimulação, com $5 \mathrm{~min}$ de intervalo entre ciclos. O primeiro ciclo consistiu em 10 estímulos de 2, 3, e 4mA, o segundo foi de 10 estímulos de 3, 4 e 5mA, e o terceiro foi de 10 estímulos de 5 e $6 \mathrm{~mA}$ (SERAFIM et al., 2010). A sonda do eletroejaculador mede $12,5 \mathrm{~cm}$ (comprimento) e 1,0cm (de diâmetro), apresentando dois eletrodos longitudinais. Cerca de $8 \mathrm{~cm}$ da sonda foi inserida no reto do animal.

O sêmen foi colhido em tubos plásticos cônicos graduados e avaliado quanto ao aspecto e coloração. $\mathrm{O} \mathrm{pH}$ foi mensurado utilizando-se fitas apropriadas (Neutralit ${ }^{\circledR}$ Merck KGaA, Darmstadt, Alemanha). A viscosidade das amostras foi avaliada de forma subjetiva. $\mathrm{O}$ volume foi aferido com o uso de micropipetas (5 a $100 \mu \mathrm{L}$ ). A motilidade (percentual de espermatozoides móveis) e o vigor (qualidade do batimento flagelar numa escala de 0-5) foram avaliados em microscópio de campo claro (Eclipse E200, Nikon, Melville, NY, USA) sob aumento de $100 \times$ e $400 \times$. No experimento, foram utilizadas apenas amostras que apresentavam motilidade espermática inicial superior a 70\% com vigor superior a 1 .

Foram confeccionados esfregaços de sêmen corados com azul de bromofenol (1:1) para avaliação da morfologia espermática e da integridade estrutural da membrana plasmática (DERIVAUX, 1980). Nos esfregaços, foram observadas 200 células/ lâmina sob microscopia de campo claro $(1000 \times)$. O teste hiposmótico foi realizado para avaliar a funcionalidade da membrana celular, utilizando- 
se uma alíquota de $5 \mu \mathrm{L}$ de sêmen em $45 \mu \mathrm{L}$ de solução a 50mOsm L-1 (SANTOS et al., 2011). Para determinar a concentração espermática, uma alíquota de $10 \mu \mathrm{L}$ de sêmen foi diluída em solução formolizada $(10 \%)$ tamponada $(1 \mathrm{~mL})$ e observada em câmara de Neubauer.

Cada amostra foi dividida em quatro alíquotas, sendo duas imediatamente diluídas em Tris [3.028g Tris-hidroximetil-aminometano, $1.78 \mathrm{~g}$ ácido cítrico mono-hidratado, e $1.25 \mathrm{~g}$ D-frutose, dissolvidos em $100 \mathrm{~mL}$ de água ultrapura; $300 \mathrm{mOsm} \mathrm{L}^{-1}$ e pH 6,8] ou água de coco em pó (ACP-119 ${ }^{\circledR} ; 310 \mathrm{mOsm} \mathrm{L}^{-1} \mathrm{e}$ $\mathrm{pH}$ 6,9), preparada de acordo com as recomendações do fabricante (ACP Biotecnologia - ACPBIOTEC, Fortaleza, CE). As outras duas alíquotas foram centrifugadas a $800 \mathrm{~g} 10 \mathrm{~min}^{-1}$ (WESTENDORF et al., 1975) para a retirada do plasma seminal, e depois diluídas nas mesmas substâncias. $\mathrm{O}$ volume de diluente foi calculado a fim de que fosse atingida a concentração final de $15 \times 10^{6}$ espermatozoides $\mathrm{mL}^{-1}$. Todas as amostras foram incubadas em banho-maria a $34^{\circ} \mathrm{C}$, temperatura corpórea do tatu-peba, para realização de um teste de termorresistência (TTR) (SANTOS et al., 2011). Neste teste, procederam-se as análises seminais a cada $60 \mathrm{~min}$ ao longo de $3 \mathrm{~h}$.

Os resultados foram expressos em média e erro padrão (média $\pm \mathrm{EP}$ ) e analisados pelo programa StatView $^{\circledR} 5.0$ para Windows (Cary, NY, USA). Com exceção dos dados de vigor, os demais resultados foram checados quanto à homocedasticidade, pelo teste de Levene, e submetidos à transformação em Arco Seno. O efeito dos tratamentos sobre os diferentes parâmetros seminais foi comparado pelo teste de Fisher PLSD. As comparações ao longo do tempo foram realizadas pela ANOVA para medidas repetidas $(\mathrm{P}<0.05)$. A ação dos mesmos efeitos sobre $\mathrm{o}$ vigor foi verificada pelo teste de Mann-Whitney $(\mathrm{P}<0,05)$.

\section{RESULTADOS}

O sêmen fresco dos tatus-peba apresentou coloração branca e aspecto leitoso-aquoso, $\mathrm{pH}$ alcalino próximo 9 e elevada viscosidade. Os ejaculados apresentaram volume de $0,7 \pm 0,5 \mathrm{~mL}$ com concentração de $225,8 \pm 161,9 \times 10^{6}$ espermatozoides $\mathrm{mL}^{-1}$. Foram observados $82,5 \pm 2,6 \%$ de espermatozoides com morfologia normal. Destes, $77,1 \pm 4,4 \%$ apresentavam motilidade com vigor $2,1 \pm 0,3$, bem como $71,2 \pm 2,6 \%$ de membranas estruturalmente íntegras ao esfregaço corado com azul de bromofenol, sendo que $62,6 \pm 4,6 \%$ apresentaram integridade funcional ao teste hiposmótico.
O procedimento de diluição, independente do uso da centrifugação, promoveu de imediato uma redução na viscosidade seminal. Entretanto, o fenômeno de rouleaux espermático, apresentandose na forma de dois ou mais espermatozoides agregados cabeça-cabeça, foi verificado no sêmen fresco e persistiu, mesmo após a diluição em ambos os diluentes testados, e no decorrer de todo o experimento.

Ao TTR, observou-se declínio $(\mathrm{P}<0,05)$ da motilidade e do vigor espermático (Figura $1 \mathrm{AB})$ já aos 60 minutos após a diluição em ambos tratamentos, sendo mais pronunciado no uso do ACP$119^{\circledR}(\mathrm{P}<0,05)$. Este declínio se acentuou ao longo dos 180 minutos, juntamente com um declínio nos valores referentes à integridade estrutural (Figura 2A) e funcional da membrana (Figura 2B). Aos 180 minutos, nas amostras não centrifugadas, foram verificados valores em torno de $20 \%$ de espermatozoides com membranas íntegras do ponto de vista estrutural e funcional, embora estivessem imóveis.

De modo geral, evidenciou-se efeito negativo da centrifugação $(\mathrm{P}<0,05)$ sobre os parâmetros seminais, ao longo do TTR, no uso de ambos os diluentes (Figuras 1 e 2). A morfologia espermática foi também avaliada no experimento, porém, não foram observados danos significativos sobre este parâmetro e, aos 180 minutos, valores próximos a $80 \%$ de espermatozoides com morfologia normal foram observados em todos os tratamentos.

\section{DISCUSSÃO}

Nos tatus-peba, a aplicação de técnicas para a preservação de sêmen encontra desafios relacionados a características inerentes à espécie, como a configuração de aglutinados espermáticos na forma de rouleaux e a alta viscosidade do plasma seminal. Estas, associadamente, contribuem para a redução fisiológica do movimento espermático progressivo (SANTOS et al., 2011), como relatado para o tatu Cabassous unicinctus (HEATH et al., 1987). Não se sabe ao certo a razão desta elevada viscosidade observada nas amostras de sêmen. Em camelos, há relatos de que seja relacionada à grande presença de glicosaminoglicanos no plasma seminal (MOSAFERI et al., 2005), proveniente de secreções da próstata ou glândulas vesiculares (CARDOSO et al., 1985). Esta característica, além de prejudicar a avaliação da qualidade do sêmen, não permite que ele se misture adequadamente aos diluentes (WANI et al., 2008; OLIVEIRA et al., 2011). 

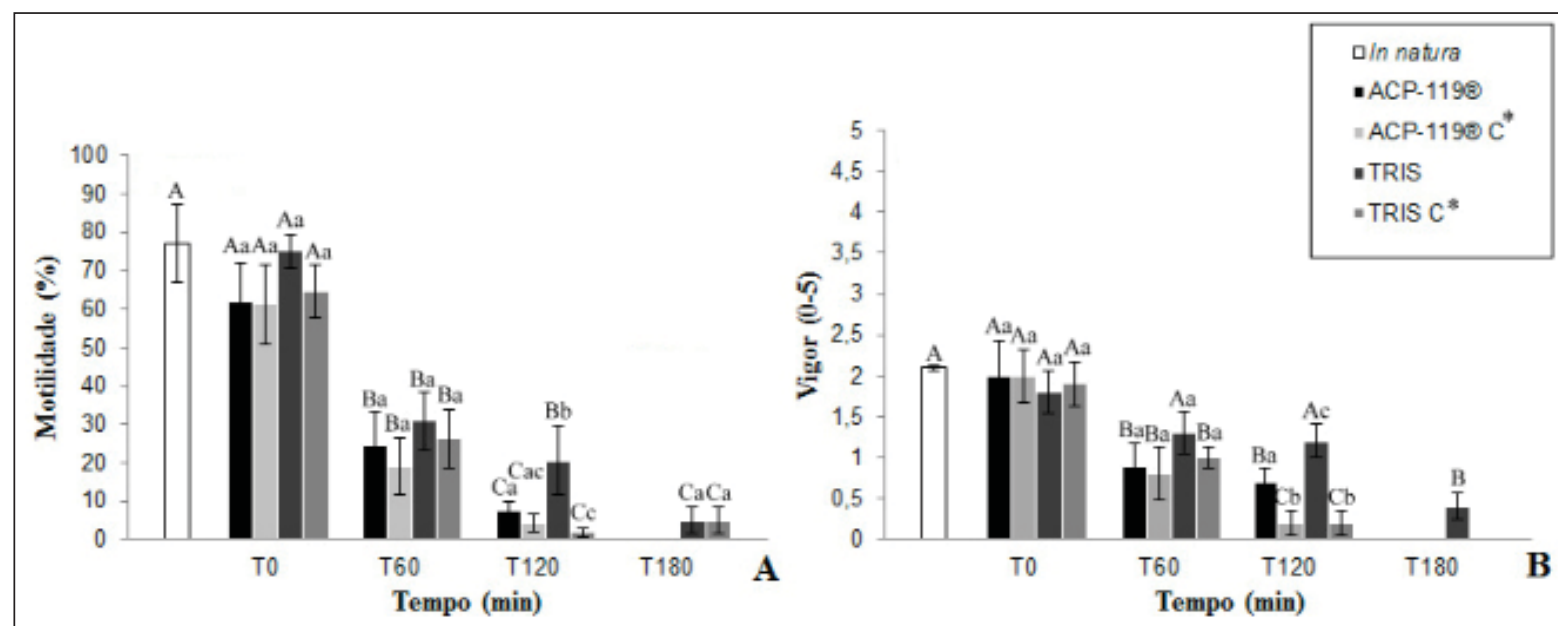

Figura 1 - Valores (média $\pm \mathrm{dp}$ ) referentes à motilidade $(\mathrm{A})$, e vigor $(\mathrm{B})$ em sêmen de tatus-peba $($ Euphractus sexcinctus $-\mathrm{n}=12$ ejaculados por grupo, derivados de 04 indivíduos) durante teste de termorresistência com diluentes Tris e ACP-119 ${ }^{\circledR}$ associados ou não à centrifugação $\left(\mathrm{C}^{*}\right)$. abcSobrescritos com letras minúsculas diferentes indicam valores com diferença significativa entre os grupos experimentais dentro de cada tempo $(\mathrm{P}<0,05)$. ${ }^{\mathrm{ABCD}}$ Sobrescritos com letras maiúsculas diferentes indicam valores com diferença significativa dentro do mesmo grupo experimental ao longo do tempo $(\mathrm{P}<0,05)$.

No presente estudo, ambos os diluentes foram eficientes em promover uma imediata redução de viscosidade no plasma seminal de tatus-peba. De fato, tanto o diluente a base de Tris quanto aquele a base de ACP- $119^{\circledR}$ já haviam sido reportados por liquefazer o coágulo seminal em camelídeos (WANI et al., 2008) e primatas (OLIVEIRA et al., 2011), respectivamente. No entanto, apesar da redução da viscosidade, a diluição não foi suficiente para impulsionar progressão aos espermatozoides, devido à persistência dos roleaux entre os espermatozoides de tatus-peba. Essas formações foram descritas em outra espécie de tatu (Cabassous unicinctus), através de imagens por ultramicroscopia, mostrando dois ou mais espermatozoides empilhados, sendo atribuídas ao formato côncavo da cabeça dos espermatozoides, o que facilita o encaixe e a permanência da junção entre essas células (HEATH et al., 1987). Este fenômeno é também descrito em marsupiais (Didelphis virginiana), nos quais se acredita que este evento coesivo favoreça a proteção dos espermatozoides durante sua passagem pelo epidídimo, sendo que sua separação deva ocorrer apenas no trato genital feminino (RODGER \& BEDFORD, 1982). Diante deste conceito fisiológico, é possível que os estudos voltados para a tecnologia de sêmen em tatus devam ser focados no desenvolvimento de métodos que permitam a preservação das células mesmo estando elas agregadas, possibilitando a manutenção de sua viabilidade e posterior separação, quando inseridas no trato genital feminino durante a inseminação artificial.
No teste de termorresistência com ambos os diluentes, verificou-se um rápido declínio da motilidade espermática, conforme previamente descrito por SANTOS et al., (2011). Porém, de modo geral, o diluente Tris permitiu uma melhor conservação que o $\mathrm{ACP}^{\circledR}$ nas avaliações realizadas aos 60 e 120 minutos. Sabe-se que a presença de citocininas, como a cinetina, na água de coco, tende, inicialmente, a aumentar o metabolismo das células (LEE et al., 2006), induzindo a depleção de ATP (CABELLO et al., 2009), quando em temperaturas elevadas, proporcionando uma mais rápida redução na motilidade espermática. Fato este que não ocorre quando o referido diluente é utilizado na preservação de células espermáticas a baixas temperaturas, conforme inclusive já demonstrado em tatus-peba (AMORIM et al., 2012).

Ao longo do TTR, não foram evidenciados danos significativos à morfologia espermática em decorrência da centrifugação. Sabe-se que a ocorrência de danos mecânicos estaria relacionada à sensibilidade característica de cada espécie, de modo que os espermatozoides de tatus-peba parecem, em parte, ser resistentes a este procedimento, conforme descrito para equinos (CROCKETTA et al., 2001) e bovinos (PICKETT et al., 1975). Entretanto, não se pode descartar a ocorrência de danos subletais ao nível manométrico, haja vista ter sido verificado um efeito deletério da centrifugação sobre a motilidade, vigor e integridade de membrana nos tatus-peba, em ambos os diluentes testados. Nos caprinos, resultados similares têm sido atribuídos a danos ultraestruturais, 

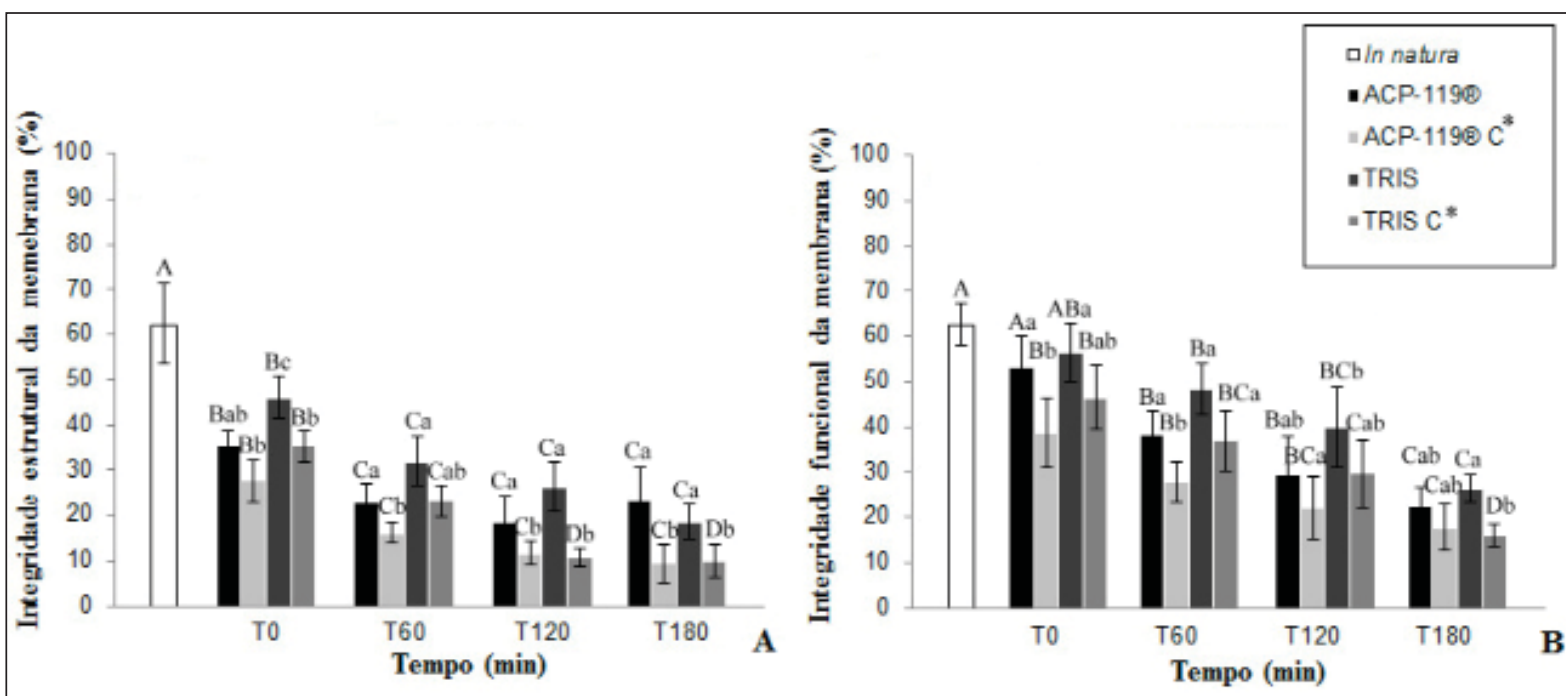

Figura 2 - Valores (média $\pm \mathrm{dp}$ ) referentes à integridade estrutural de membrana determinada com azul de bromofenol (A) e integridade funcional de membrana determinada pelo teste hiposmótico (B) em sêmen de tatus-peba (Euphractus sexcinctus - n=12 ejaculados por grupo, derivados de 04 indivíduos) durante teste de termorresistência com diluentes Tris e ACP- $119^{\circledR}$ associados ou não à centrifugação $\left(C^{*}\right)$. ${ }^{\text {abc }}$ Sobrescritos com letras minúsculas diferentes indicam valores com diferença significativa entre os grupos experimentais dentro de cada tempo $(\mathrm{P}<0,05) .{ }^{\mathrm{ABCD}}$ Sobrescritos com letras maiúsculas diferentes indicam valores com diferença significativa dentro do mesmo grupo experimental ao longo do tempo $(\mathrm{P}<0,05)$.

apenas visualizados sob microscopia eletrônica, causados pela centrifugação, e podendo ocasionar redução da viabilidade e, consequentemente, perda da fertilidade (VIANA et al., 2006).

O uso de corantes supravitais, como o azul de bromofenol, detecta a integridade física da membrana plasmática, enquanto o teste hiposmótico avalia se ela está bioquimicamente ativa (ARRUDA et al., 2011). Assim, através do teste hiposmótico, verificou-se que o Tris promoveu uma melhor conservação do percentual de espermatozoides com membrana bioquimicamente ativa no sêmen de tatus-peba. Apesar do $\mathrm{ACP}^{\circledR}$ ser rico em proteínas, sais, açúcares, entre outras substâncias (BARROS \& TONIOLLI, 2011), é possível que o Tris possua uma concentração de eletrólitos mais adequada para manter por um período maior a pressão osmótica fisiológica do sêmen de tatus-peba. Necessário também salientar que os gametas de diferentes espécies respondem de modo diferenciado aos meios aos quais são expostos (PURDY, 2006). Muitas vezes, a razão desta variação é inerente à composição bioquímica de sua membrana plasmática ou a componentes intracelulares que permanecem por serem melhor estudados (HOLT, 2000).

De modo geral, na comparação dos diluentes, observou-se uma melhor eficiência do Tris quanto à preservação dos parâmetros seminais ao longo do TTR, principalmente até os $120 \mathrm{~min}$ de avaliação. Após este período, os dois diluentes se equipararam. Diante disso, conclui-se que o diluente Tris mostrou-se superior ao ACP $-119^{\circledR}$ para a manutenção da viabilidade do sêmen de tatus-peba. Em adição, não se recomenda a centrifugação das amostras previamente à diluição, haja vista o efeito negativo que esta exerce sobre a viabilidade seminal.

\section{COMITÊ DE ÉTICA E BIOSSEGURANÇA}

Os procedimentos foram realizados de acordo com as normas internacionais de bem estar animal e aprovados pela Comissão de Ética no Uso de Animais da UFERSA, recebendo parecer no 21/2011, referente ao processo 23091.002754/2011-99.

\section{AGRADECIMENTOS}

Os autores agradecem ao Conselho Nacional de Desenvolvimento Científico ( $\mathrm{CNPq})$ pela concessão de bolsa de mestrado para P. C. Souza e produtividade em pesquisa para A. R. Silva.

\section{REFERÊNCIAS}

ALVAREZ-RODRÍGUEZ, M. et al. The addition of heat shock protein HSPA8 to cryoprotective media improves the survival of brown bear (Ursus arctus) spermatozoa during chilling and after cryopreservation. Theriogenology, v.79, p.541-50, 2013. Disponível em: <http://dx.doi.org/10.1016/j. theriogenology.2012.11.006>. Acesso em: 24 out. 2013.

AMORIM, R.N.L. et al. Short-term preservation at $5^{\circ} \mathrm{C}$ of Armadillo's (Euphractus sexcinctus) semen. In: INTERNATIONAL SYMPOSIUM ANIMAL BIOLOGY OF REPRODUCTION, 
ISABR, 3., 2012, Campinas, SP. Anais... Campinas: IV International Symposium on Animal Biology of Reproduction, 2012. V.9, p.971. Disponível em: <http://www.cbra.org.br/portal/eventos/isabr2012/ IV\%20ISABR\%20Poster\%20session\%20list\%202012-10-05.pdf>. Acesso em: 24 out. 2013.

ANACLETO, T.C.S. et al. Estimating potential geographic ranges of armadillos (Xenarthra, Dasypodidae) in Brazil undernichebased models. Mammalia, v.70, p.202-213, 2006. Disponível em: <http://dx.doi.org/10.1515/MAMM.2006.039>. Acesso em: 24 out. 2013 .

ARRUDA, R.P. et al. Métodos de avaliação da morfologia e função espermática: momento atual e desafios futuros. Revista Brasileira de Reprodução Animal, v.35, p.145-151, 2011. Disponível em: $<$ http://www.cbra.org.br/pages/publicacoes/rbra/v35n2/RB385\%20 Arruda\%20145-151.pdf>. Acesso em: 24 out. 2013.

BARROS, T.B.; TONIOLLI, R. Uso potencial da água de coco na tecnologia de sêmen. Revista Brasileira de Reprodução Animal, v.35, p.400-407, 2011. Disponível em: <http://www.cbra.org.br/pages/ publicacoes/rbra/v35n4/pag\%20400-407.pdf>. Acesso em: 24 out. 2013.

CABELLO, C.M. et al. The experimental chemotherapeutic N6-furfuryladenosine (kinetin-riboside) induces rapid ATP depletion, genotoxic stress, and CDKN1A (p21) up regulation in human cancer cell lines. Biochemical Pharmacology, v.77, p.1125-1138, 2009. Disponível em: <http://dx.doi.org/10.1016/j. bcp.2008.12.002>. Acesso em: 23 out. 2013.

CARDOSO, F.M. et al. Variação sazonal da atividade secretória das glândulas genitais acessórias masculinas de tatus Dasypus Novemcinctus Linnaeus, 1758. Revista Brasileira de Biologia, v.45, p.507-514, 1985.

CASTELO, T.S. et al. Effect of centrifugation and sugar supplementation on the sêmen cryopreservation of captive collared peccaries (Tayassu tajacu). Cryobiology, v.61, p.275-279, 2010. Disponível em: <http://dx.doi.org/10.1016/j. cryobiol.2010.09.005>. Acesso em: 24 out. 2013.

CROCKETTA, E.C. et al. Effect of cooling equine spermatozoa before freezing on post-thaw motility: preliminary results. Theriogenology, v.57, p.793-803, 2001. Disponível em: <http:// dx.doi.org/10.1016/S0093-691X(01)00444-7>. Acesso em: 24 out. 2013.

DERIVAUX, J. Reprodução dos animais domésticos. Zaragoza: Acribia, 1980. 446p.

HEATH, E. et al. Rouleaux formation by spermatozoa in the nakedtail armadillo, Cabassous unicinctus. Journal Reproduction Fertility, v.79, p.153-158, 1987. Disponível em: <http://dx.doi. org/10.1530/jrf.0.0790153>. Acesso em: 23 out. 2013.

HOLT, W.V. Fundamental aspects of sperm cryobiology: the importance of species and individual differences. Theriogenology, v.53, p.47-58, 2000. Disponível em: <http://dx.doi.org/10.1016/ S0093-691X(99)00239-3>. Acesso em: 23 out., 2013.

IUCN. Lista vermelha de espécies ameaçadas da International Union for Conservation of Nature. 2013. Disponível em: $<$ http://www.iucnredlist.org/search/details.php/8306/all >. Acesso em: 05 jan. 2013.

LEE, H.S. et al. Physiological enhancement of early growth of rice seedlings (Oryza sativa L.) by production of phytohormone of N2-fixing methyolotrophic isolates. Biology and Fertility of Soils, v.42, p. 402-408, 2006. Disponível em: <http://dx.doi. org/10.1007/s00374-006-0083-8>. Acesso em: 24 out. 2013.

MOSAFERI, S. et al. Biophysical and biochemical characteristics of Bactrian camel semen collected by artificial vagina. Theriogenology, v.63, p.92-101, 2005. Disponível em: <http:// dx.doi.org/10.1016/j.theriogenology.2004.03.021>. Acesso em: 24 out. 2013.

OLIVEIRA, K.G. et al. Semen coagulum liquefaction, sperm activation and cryopreservation of capuchin monkey (Cebus apella) semen in coconut water solution (CWS) and TES-TRIS. Animal Reproduction Science, v.123, p.75-80, 2011. Disponível em: $<$ http:// dx.doi.org/10.1016/j.anireprosci.2010.11.002>. Acesso em: 24 out. 2013 .

PICKETT, B.W. et al. Effect of centrifugation and seminal plasma on motility and fertility of stallion and bull spermatozoa. Fertil Sterility, v.26, p.167-174, 1975.

PURDY, P. A review on goat sperm cryopreservation. Small Ruminant Research, v.63, p.215-225, 2006. Disponível em: $<$ http://dx.doi.org/10.1016/j.smallrumres.2005.02.015>. Acesso em: 24 out. 2013.

RODGER, J.C.; BEDFORD, J.M. Separation of sperm pairs and sperm-egg interaction in the opossum Didelphis virginiana. Journal of Reproduction and Fertility, v.64, p.171-179, 1982. Disponível em: < http://dx.doi.org/10.1530/jrf.0.0640171>. Acesso em: 24 out. 2013.

SANTOS, E.A.A. et al. Assessment of sperm survival and functional membrane integrity of the six-banded armadillo (Euphractus sexcinctus). Theriogenology, v.76, p.623-629, 2011. Disponível em: $<$ http://dx.doi.org/10.1016/j.theriogenology.2011.03.015>. Acesso em: 23 out. 2013.

SERAFIM, M.K.B. et al. Description of semen characteristics from six-banded armadillos (Euphractus sexcinctus) collected by electroejaculation. Animal Reproduction Science, v.118, p.362-365, 2010. Disponível em: <http://dx.doi.org/10.1016/j. anireprosci.2009.08.012>. Acesso em: 23 out. 2013.

SOUSA, P.C. et al. Morphology, morphometry and ultrastructure of captive six-banded armadillo (Euphractus sexcinctus) sperm. Animal Reproduction Science, v.140, p.279285, 2013. Disponível em: <http://dx.doi.org/ 10.1016/j. anireprosci.2013.05.015>. Acesso em: 15 out. 2013.

VIANA, A.K.S. et al. Avaliação in vitro do sêmen caprino resfriado, com ou sem centrifugação do plasma seminal e diluído em desnatado-glicose e tris-gema de ovo. Ciência Animal Brasileira, v.7, p.67-76, 2006. Disponível em: <http://www. revistas.ufg.br/index.php/vet/article/view/386>. Acesso em: 23 out., 2013.

WANI, N.A. et al. Studies on liquefaction and storage of ejaculated dromedary camel (Camelus dromedarius) semen. Animal Reproduction Science, v.109, p.309-318, 2008.

WESTENDORF, P. et al. Tiefgefrierung von Ebersperma. Labor-und Besamungsergebnisse mit dem Hu"lsenberger Paillettenverfahren. DtschTierärztl Wschr, v.82, p.261-267, 1975. 